\title{
Ambivalence about Social Welfare: An Evaluation of Measurement Approaches
}

\author{
Jason Gainous
}

\begin{abstract}
Research across disciplines, including political science, has embraced the idea that individuals often possess ambivalent attitudes, but there is considerable disagreement about how to measure this phenomenon. Determining an effective way of capturing such phenomena is important to our understanding of politics and public opinion. The literature offers several meta-attitudinal and operative measures of ambivalence. I discuss strengths and weaknesses of each of these approaches and conduct a test of the relative construct validity of two meta-attitudinal and two operative measures of social welfare ambivalence using data from a statewide survey of Florida residents in 2004. The findings suggest that one of the operative measures that forces respondents to rate their positive and negative feelings separately performs better than any of the other approaches currently offered.
\end{abstract}

The idea that people's attitudes are a mix of considerations that may result in ambivalence is becoming accepted across disciplines. Ambivalence is defined as the simultaneous possession of positive and negative evaluations of a single attitude object (Albertson, Brehm, and Alvarez 2005; Alvarez and Brehm 1995; Armitage and Connor 2000; Cacioppo, Gardner, and Berntson 1997; Craig, Kane, and Martinez 2002; Eagly and Chaiken 1993; Gainous and Martinez 2005; McGraw, Hasecke, and Conger 2003; Newby-Clark, McGregor, and Zanna 2002; Priester and Petty 1996; Zaller 1992). The problem today is that most survey research is still treating attitudes as if they were uni-polar. Simply, most survey indicators do not offer any systematic way of separating those who are ambivalent from those who are not. Those who are ambivalent are typically forced to pick a side or select a neutral response. The literature does offer several approaches to isolating the ambivalent; but there is no agreement as to which is preferable. This stems from disagreement regarding how ambivalence is conceptualized. In the following paper, I evaluate these measurement strategies. Specifically, I conduct a test of the relative construct validity of two meta-attitudinal and two operative measures of social welfare ambivalence.

I focus on social welfare policy because this is an issue domain where a non-trivial amount of ambivalence has been uncovered (Feldman and Zaller 1992; Cantril and Cantril 1999; Gainous and Martinez 2005; Hodson, Maio,

I would like to thank Stephen C. Craig, Jeff Gill, Michael D. Martinez, Laurie Rhodebeck, Kenneth D. Wald, Ken Webber, and the anonymous reviewers for their helpful comments.

JASON GAINOUS is an assistant professor of political science at the University of Louisville.

The American Review of Politics, Vol. 29, Summer, 2008: 109-134

(c)2008 The American Review of Politics 
and Esses 2001). If the intention is to compare meta-attitudinal and operative measures of ambivalence, it needs to be done in an area where we expect the phenomenon to be present. Social welfare policy is a good candidate.

Meta-attitudinal measures of ambivalence simply ask respondents in various ways to state whether they are torn between sides on the issue at hand. Operative measures of ambivalence employ some means to ascertain the degree to which individuals are ambivalent without making respondents aware that this phenomenon is being measured. Prior research indicates that the correlations between meta-attitudinal and operative measures of ambivalence are modest in magnitude (Newby-Clark, McGregor, and Zanna 2002; Priester and Petty 2001). If ambivalence is conceptualized as the simultaneous possession of opposing feelings, then meta-attitudinal measures may often be indicators of uncertainty or nonattitude rather than ambivalence in the strictest terms. Operative measures provide the opportunity to remove the subjectivity of the respondent. Based on this reasoning, I expect that an operative measure which gauges positive and negative feelings separately will be a more accurate representation of ambivalence.

Earlier work assesses the relative validity of both approaches by looking at how well ambivalence predicts the variance of its theoretical consequences (Bassili 1996; Holbrook and Krosnick 2005). Construct validity should also be evaluated by estimating how well the variance of ambivalence is predicted by its theoretical sources. This is where the present study comes in. If a measure is valid, or at least has construct validity, the theoretical correlates of the measure should serve as reliable predictors. Accordingly, I compare how well the theoretical sources of ambivalence including cognitive, affective, and cognitive-affective conflict predict each of the meta-attitudinal and operative measures. This test has two obvious assumptions: first, theory suggesting the likely sources of ambivalence is accurate, and second, measures of the sources of ambivalence are valid. As detailed below, theory in regards to the former is fairly well developed. Concerning the latter, the measures of the sources used here are based on standard indicators of values and group affect used in the American National Election Studies (ANES), so their validity has been repeatedly confirmed.

The results presented here suggest that an operative measure of social welfare ambivalence which forces respondents to rate their positive and negative feelings separately will perform better than any of the other approaches currently offered in the literature. Before discussing these results, I briefly make the case for why we should care about ambivalence. This is followed by a critique of meta-attitudinal and operative approaches to measurement and a review of the potential sources of ambivalence. Then the measures are detailed and the results presented, including a fully specified model of social welfare ambivalence. 


\section{Why Measure Ambivalence?}

While survey researchers have begun to accept that ambivalence is a standard attribute of attitudes (Alvarez and Brehm 1995; Craig, Kane, and Martinez 2002; Feldman and Zaller 1992; Zaller 1992), our measures have not caught up with theory. If ambivalence is a standard attribute of attitudes along with such other attributes as attitude importance (Krosnick and Abelson 1992; Krosnick 1988; Boninger, Krosnick, Berent 1995), intensity (Krosnick and Abelson 1992; Krosnick et al. 1993), extremity and certainty (Alvarez and Brehm 1995), and these attributes are consequential to our understanding of attitudes in general (see Bassili 1996 for a review), it seems logical that we should determine the optimal way to measure the attribute of ambivalence. We have standard approaches in survey research to capture these other phenomena, such as Likert and rating scales which capture both intensity and extremity by having options to the left and right of the midpoint, and certainty and importance by simply asking respondents to rate these attributes on scales of such, but no standard way to isolate ambivalence. While ambivalence may certainly be related to all of these attributes, it is a separate attribute. Therefore, it seems imperative to our understanding of attitudes in general that we develop such a measure.

If standard indicators used in the major surveys utilized in the discipline (e.g. American National Election Studies and General Social Survey) offer no systematic way of distinguishing those who are ambivalent from those who are not, it is likely that the results of many of the studies that used these data are questionable. This is especially true when it comes to those that focus on attitudes about issues where ambivalence may be prevalent. For example, let us assume that social welfare ambivalence is widespread and that social welfare policy preferences are related to candidate evaluations. If a model of these evaluations accounts for policy preferences but not for ambivalence about the policy, the estimate for the effect of policy preferences will be biased. The relationship may appear to be stronger or weaker than it actually is. The exclusion of ambivalence does not mean that previous research results are completely without merit, but it certainly suggests that some studies may need fine-tuning.

We need accurate measures of ambivalence not only to eliminate bias in our estimates of public opinion, but also because ambivalence has real political consequences. For example, research has indicated that the relationship between issue attitudes and evaluations of political leaders is moderated by ambivalence (Craig et al. 2005). Research has also suggested that ambivalence is related to less interest in learning issue-relevant information, to less perceived hostile media bias, and to increased reports of general activism (Holbrook and Krosnick 2005). These are just a few examples of the 
political consequences of ambivalence. Again, the point is that ambivalence is indeed consequential. Thus, we need accurate measures of this phenomenon.

\section{Critique of Previous Approaches to Measuring Ambivalence}

\section{Meta-Attitudinal Measures}

Meta-Attitudinal measures of ambivalence require respondents to state directly that they have opposing feelings. For example, respondents may be asked whether their attitudes are one-sided or mixed or whether they agree with statements like "I have positive and negative feelings about . ..". For example, Priester and Petty $(1996,2001)$ asked respondents to complete a series of 10-point scales designed to assess the extent to which their reactions were conflicted, mixed, and indecisive with respect to the attitude objects under observation. ${ }^{1}$ Using a typical large-sample survey, Mulligan and McGraw (2002) also employed a meta-attitudinal measure of ambivalence using the following indicator:

Some people feel that there are only good things or bad things about this issue (a. government wiretapping, b. social welfare spending). Their feelings are consistent. Other people feel that there are both good things and bad things about this issue. Their feelings are inconsistent. Thinking about your own views, would you say that your feelings about this issue are extremely consistent, very consistent, somewhat consistent, somewhat inconsistent, very inconsistent, or extremely inconsistent?

While other researchers have used slightly different wording, these two examples exemplify the meta-attitudinal approach, at least broadly.

A strength of the meta-attitudinal approach is that it is practical. It requires one simple question that allows respondents to state if they are conflicted or mixed. In practice, we are often faced with trade-offs in survey research because of financial and time limitations. We can only have so many questions on any given instrument. With this approach, there is no need to have multiple questions gauging positive and negative responses separately. Thus, it is the least costly method.

On the other hand, the meta-attitudinal approach treats ambivalence as a subjective experience rather than as an attribute of attitudes in general. If this is the case, then perhaps respondents are not in the best position to make a diagnosis. A medical doctor asks patients what their symptoms are and then makes a diagnosis. The meta-attitudinal approach essentially asks respondents to diagnose themselves. This is probably not the best way to capture the phenomenon of an individual simultaneously possessing positive 
and negative evaluations of a single attitude object. Allowing respondents to assess the degree to which they possess these evaluations may allow extraneous factors to distort the measure.

\section{Operative Measures}

Operative measures of ambivalence involve some method of gauging the extent to which ambivalence exists without depending on an individual's personal assessment. While several different strategies have been employed, they all share this common thread. What sets early strategies apart from later ones is that they involved the subjectivity of the researchers. For example, Feldman and Zaller (1992) asked survey respondents to state whatever thoughts came to mind as they answered two traditional closed-ended policy questions. Then they measured ambivalence by counting the number of conflicting considerations, spontaneous statements of ambivalence, and twosided remarks (i.e., "Although I think X, I nevertheless favor Y"), finding strong support for the presence of ambivalence in many of the respondents. This can be thought of as an operative measure of ambivalence because respondents were not asked to assess their own degree of ambivalence. However, this approach certainly required the subjective assessment of the researchers.

Alvarez and Brehm (1995, 1997, and 1998) and Jacoby (2002) employ another variation of the operative approach. They inferred the presence of ambivalence in respondents' attitudes from patterns of error variance in heteroskedastic probit and ordinary least squares regression models respectively. This measurement strategy involves analyzing the residuals of a model of the attitude object under examination. Residuals are the difference between the value for each respondent predicted from the probit equation and the actual observed response of that individual. They contend that the variance of these residuals should be higher among those who are ambivalent. Essentially, Jacoby and Alvarez and Brehm each test to see if the residual variance is higher among those who theory suggests should be ambivalent (e.g., those with values in conflict).

Others have used another operative approach to measuring ambivalence where respondents are asked to rate how positively they feel toward an attitude object and then asked separately to rate how negatively they feel toward the object (Craig, Kane, and Martinez 2002; Craig, Martinez, and Kane 2005; Gainous and Martinez 2005; Martinez et al. 2005). The responses are then combined via a mathematical algorithm, yielding an ordinal measure of ambivalence.

A strength of all of these operative approaches is that they all treat ambivalence as an attribute of attitudes in general as opposed to a subjective 
experience. In this case, attitudes are a mix of multiple considerations (Zaller 1992), and the Feldman and Zaller approach as well as the strategy used by Craig and his colleagues give respondents the opportunity to express explicitly these multiple considerations. Alvarez and Brehm (1995, 1997, and 1998) clearly separate the respondent's direct assessments of how mixed they are from the measurement, but they do not give respondents the opportunity to rate, simultaneously, how positively and negatively they feel toward the object at hand. This is where the approach used by Craig and his colleagues is the strongest. The operational definition they use most closely fits the conceptual definition offered in the psychology literature: the simultaneous possession of opposing feelings.

The weakness of these operative approaches varies for each. Concerning Feldman and Zaller's approach, the possession of "opposing considerations" may in fact indicate the presence of factors other than ambivalence such as equivocation (someone is trying not to make a bad impression on the interviewer), uncertainty (they are unsure of which side of the issue to choose), informedness (the respondent has sufficient information to cite both sides evenly while clearly favoring one or neither), or nonattitude (the respondent has no real position on the issue), or the questions may be ambiguous making them insufficient as indicators of preference (see Alvarez and Brehm 1995, 1997, 1998). Therefore, the possession of opposing considerations is not necessarily a product of or representative of ambivalence. Remember that ambivalence defined as an attribute of attitudes refers to conflict about a single attitude object. Expressing conflicting viewpoints that are not explicitly about the same object is not ambivalence.

Alvarez and Brehm (1995) and Jacoby (2002) define ambivalence appropriately but use a measure that does not accurately represent their conceptualization. Inferring ambivalence from patterns of residual variance is problematic on two levels. First, ambivalence is an individual-level concept and their inferences are essentially based upon aggregate-level data (error variance in a predictive model across groups). Second, these measures fail to distinguish ambivalence from the very things Alvarez and Brehm suggest are problematic with the Feldman and Zaller study (equivocation, uncertainty, informedness, and nonattitude). Error variance could be a result of these factors. They control for levels of political knowledge to account for such, but this approach still requires more assumptions than the other operative approach.

There are a couple of obvious weaknesses with the measure used by Craig and his colleagues and by Gainous and Martinez. The first problem is that questioning about positive and negative feelings separately can involve complicated wording, which may confuse respondents. The next problem is a practical one. For each attitude object, they ask two questions. Surveys are 
expensive and if it is necessary to ask two questions for every one attitude object, the financial cost will increase. This may limit the number of objects or issues that can be included. Also, because it makes the survey longer, response rates would likely significantly drop off. Aside from this practical problem, this approach seems to be the closest representation of ambivalence, properly defined.

\section{Comparing Meta-attitudinal and Operative Approaches}

Bassili (1996) compares the validity of meta-attitudinal and operative measures of ambivalence by looking at how well ambivalence predicts attitude strength. His findings suggest that operative measures have more predictive validity. He suggests that two realms of psychological functioning exist: one comprised of operative psychological processes and the other comprised of impressions of these processes. This may be true for ambivalence as well. Meta-attitudinal measures of ambivalence may be picking up people's reaction to feeling ambivalent rather than the actual phenomena. If reactions vary, then the meta-attitudinal measure is capturing something other than the phenomena itself. Rather, it may be the byproduct of ambivalence.

Thompson and her colleagues (1995) looked at the relationship between meta-attitudinal and operative measures of ambivalence and also found them to be only moderately related (see also Newby-Clark, McGregor, and Zanna 2005; Priester and Petty 1996), but they did not offer a test of construct validity. Holbrook and Krosnick (2005) offer a more thorough evaluation of the relative validity of these approaches finding that each represents a distinct construct having different consequences for cognition and behavior. While both Bassili (1996) and Holbrook and Krosnick (2005) evaluate the validity of operative and meta-attitudinal measures of ambivalence, their evaluation is incomplete. Traditionally, construct validity is assessed two ways. First, it is evaluated by looking at how well the measure predicts the variance of outcomes theory suggests it should. Second, construct validity is assessed by estimating how well the variance of the measure is predicted by indicators of the theoretical explanations of the phenomenon. So, to fully assess construct validity we should look at the performance of a measure as both an independent and dependent variable. Both Bassili (1996) and Holbrook and Krosnick (2005) look at the former and I look at the latter. By doing so, I add to their findings by providing additional support to the idea that operative measures of ambivalence perform better. While I draw similar conclusions, my approach helps complete what they started. Hence, I focus on the potential sources of ambivalence and compare how well these sources predict each measure. 


\section{Theoretical Sources of Ambivalence}

The literature offers three primary sources of ambivalence including cognitive conflict, affective conflict, and cognitive-affective conflict (Feldman and Zaller 1992; Martinez et al. 2005; Steenbergen and Brewer 2000). The basic idea is simple. People make decisions and form attitudes by using such cognitive and affective shortcuts as party identification, media cues, values, and feelings about groups among many others. These shortcuts permit individuals to make reasonable decisions with minimal effort (Fiske and Taylor 1991; Popkin 1991). Research contends that these cognitive and affective sources of attitudes may come into conflict, and as a result, stimulate ambivalence.

Value conflict is the most often mentioned cognitive source of ambivalence in the literature (Alvarez and Brehm 1995; Eagly and Chaiken 1993; Feldman and Zaller 1992; Katz and Hass 1988; Katz, Wackenhut, and Hass 1986; Martinez et al. 2005; Newby-Clark, McGregor, and Zanna 2005). Values such as egalitarianism and economic individualism may come into conflict and stimulate ambivalence about social welfare (Feldman and Zaller 1992; Gainous and Martinez 2005). Yet even if the assumption here is correct, it is possible that value hierarchies (Rokeach 1973; Schwartz 1992; Jacoby 2002) exist and are structured in ways that sometimes serve to reduce the likelihood of ambivalence occurring. If an individual places more importance on one value than another, and if an issue arises that happens to pit these values against each other, the conflict won't necessarily matter; simply, the preferred value will prevail and determine the person's response to the issue in question.

Research has also suggested that group affect or feelings about the perceived beneficiaries of welfare structure attitudes about the issue (Bobo and Kluegel 1993; Cook and Barrett 1992; Gilens 1995; Jacoby 2005; Kinder and Winter 2001; Nelson 1999; Sniderman, Brody, and Tetlock 1991) ${ }^{2}$ and conflicting feelings may stimulate ambivalence (Lavine and Steenbergen 2005; Steenbergen and Brewer 2000). Likewise, conflict between values and group affect may also stimulate such ambivalence (Steenbergen and Brewer 2000).

\section{Data and Measurement}

The present study is based on a telephone poll conducted from May 1022, 2004, by the Florida Voter survey organization. Six hundred seven respondents were chosen randomly from a list of all registered voters in the state of Florida. Only those whose names were drawn from the list were actually interviewed. Up to four callbacks were attempted on all working 
numbers and initial refusals. The margin of error is plus or minus four percentage points. ${ }^{3}$ This survey offers both operative and meta-attitudinal measures of ambivalence along with indicators of the major sources of ambivalence making it ideal for the purposes of this study.

\section{Dependent Variables}

The dependent variable, social welfare ambivalence, is measured using two meta-attitudinal measures of ambivalence and two objective measures. The meta-attitudinal measures are derived from a split-sample experimental question contained in the instrument. Half of the sample was asked the following question:

Some people think the government should provide fewer services, even in areas such as health and education, in order to reduce spending. Others feel it is important for the government to provide more services to citizens even if it means an increase in spending. Which of these positions is closest to your own views, or are you torn between the two?

The other half of the sample was asked the following question:

Some people think the government should provide fewer services, even in areas such as health and education, in order to reduce spending. Others feel it is important for the government to provide more services to citizens even if it means an increase in spending. Which of these positions is closest to your own views?

After each, respondents were asked how strongly they felt about their position, and for the latter, interviewers were instructed to record any volunteered response that indicated the respondent was mixed or torn between sides as mixed. This created a 5-point scale ranging from fewer services/ strongly to more services/strongly with torn or mixed responses in the middle for both indicators. Dummy variables were constructed from each of these indicators coding torn or mixed responses as 1 and other responses as 0 . While it would be preferable to have meta-attitudinal measures that gauged the strength of ambivalence, these are what are available in these data. Further, they still represent the subjective experience of ambivalence.

The first operative measure was based on the design Thomson and her colleagues (1996) used that was then modified by Craig and his colleagues (2002, 2005). Respondents were asked to indicate both how positively and how negatively they viewed several aspects of social welfare policy, using batteries of questions that were introduced as follows:

I'm now going to read you a series of statements about the kinds of things some people think the government should be doing to address certain 


\section{8 | Jason Gainous}

problems that are facing the country. After each, I'd like you to rate the statement on a 4-point scale to indicate how positively you feel toward it. If you do not have any positive feelings, give it the lowest rating of 1 ; if you have some positive feelings, rate it a 2; if you have generally positive feelings, rate it a 3; and if you have extremely positive feelings, rate it a 4. Please rate each statement based solely on how positively you feel about it, while ignoring or setting aside for the moment any negative feelings you may have. The first statement is ...

The statements were then read and respondents were asked to rate each one separately. Then, following a number of filler questions, the introduction was repeated except with the words "positive" and "positively" replaced by "negative" and "negatively." If a person seemed unsure or confused at any point, interviewers were told to repeat the instructions as many times as necessary.

The specific aspects of social welfare policy that respondents were asked to evaluate are as follows: "The government should ..."

- ensure that every citizen has adequate medical insurance;

- provide programs to help homeless people find a place to live;

- ensure that every child has access to a good education;

- provide programs that improve the standard of living of poor Americans;

- see to it that everyone who wants a job has one;

- provide childcare programs to assist working parents;

- ensure that the retirement benefits that citizens have built up over the years are protected.

An index of ambivalence about social welfare policy was calculated using an algorithm developed by Thompson and her colleagues (1995; also see Kaplan 1972). ${ }^{4}$ Specifically,

$$
\text { Ambivalence }=[(\mathrm{P}+\mathrm{N}) / 2]-|\mathrm{P}-\mathrm{N}|
$$

where $\mathrm{P}$ is the positive reaction score and $\mathrm{N}$ is the negative reaction score. The range of scores for each of the seven items described above is -0.5 through 4.0, with intervals of 0.5 (see Craig, Kane, and Martinez 2002). A principal components factor analysis confirmed that all seven load on a single factor, and the reliability of an additive index constructed from them is very high $(\alpha=.860)$.

The next operative measure of ambivalence used a method similar to that employed by Alvarez and Brehm (1995, 1997, 1998, and 2002) and Jacoby (2002). Again, this measurement strategy involves analyzing the residuals of a model of the attitude object under examination. Residuals are 
the difference between the value for each respondent predicted from the ordered logit equation and the actual observed response of that individual. The idea here is that the fit of the equation to the data should be worse among individuals who are ambivalent because the range of acceptable responses for them is greater, simply because their attitude is not uni-polar. I extracted the residuals from a model of social welfare attitudes using ordered logit rather than probit (Alvarez and Brehm 1995, 1997, 1998, 2002) or ordinary least squares (Jacoby 2002) because attitudes about social welfare were measured using the ordinal scale described above for the metaattitudinal measures of ambivalence. Both groups (those who chose the torn response and those who offered a mixed response) were combined for purposes of the analysis here. ${ }^{5}$ This scale is modeled as a function of the most often cited sources of attitudes about government spending on social welfare including individualism, egalitarianism, feelings about the beneficiaries, party identification, race, gender, and income (see Bobo and Kluegel 1993; Feldman and Zaller 1992; Gilens 1988, 1995; Goren 2001; Jacoby 2005; Kaufmann and Petrocik 1999; Kinder and Winter 2001; Tate 1994). Then, the residuals from the ordered logit estimates are extracted to create a new variable. $^{6}$ The operationalization of each of these variables is described below.

\section{Independent Variables}

Now we can move to the measurement of the potential sources of ambivalence. For cognitive conflict, separate indicators of individualist and egalitarian values were constructed first. Respondents were read a series of companion statements and asked to say which came closer to their own opinion. For individualism, ${ }^{7}$ the item pairs were:

- The government should see to it that every person has a job and a good standard of living; or, the government should just let each person get ahead on their own.

- We need a strong government to handle today's complex economic problems; or, the free market can handle these problems without government being involved.

For egalitarianism, the item pairs were:

- We have gone too far in pushing equal rights in this country; or, we should do more to make sure that everyone is treated equally.

- If people were treated more equally in this country, we would have many fewer problems; or, this country would be better off if we worried less about how equal people are. 
In all cases, responses were coded from 1 (strong support for the first statement in the pair) to 5 (strong support for the second statement); for the second egalitarianism pair, this scoring was reversed to provide consistency in direction of wording. The two sets of items were then combined into indices with scores ranging from 2 to 10 (high values reflecting stronger support for individualist or egalitarian values). ${ }^{8}$

A measure of cognitive conflict, which captures the magnitude of the difference between individualist and egalitarian values, was then calculated using the same algorithm as the one described earlier for measuring social welfare ambivalence; that is,

$$
\begin{aligned}
\text { Cognitive Conflict }= & {[\text { individualism }+ \text { egalitarianism }] / 2 } \\
& -\mid \text { individualism }- \text { egalitarianism } \mid
\end{aligned}
$$

with higher values representing more conflict. This item was rescaled to have values between 0 and 1 .

As mentioned earlier, research has also suggested that the effects of value conflict on ambivalence are dependent on the personal importance people place on their values respectively (Gainous and Martinez 2005). As one value becomes more important, ambivalence should decrease. Value importance is based on responses to two separate items, introduced as follows: "As you know, not everyone agrees on the different goals or values that our nation ought to pursue. I'm going to list three ${ }^{9}$ different goals and have you tell me how important each of them is to you personally." The importance of egalitarianism and individualism was then determined based on answers to a pair of questions:

- The first goal is equality, by which we mean a narrowing of the gap in wealth and power between rich and poor. How important is equality to you - extremely important, important, only somewhat important, or not important at all? ...

- And the third goal is a free marketplace, by which we mean all citizens having a chance to get ahead on their own without the government getting involved. How important is a free marketplace to you-extremely important, important, only somewhat important, or not important at all?

Responses were recoded so that higher values represent greater importance. In addition, the relative importance of one value as opposed to the other was calculated as the absolute value of the difference between individualism importance and egalitarianism importance; higher numbers indicate that one of these values has priority over the other for the individual. For instance, someone who said one value was extremely important and the other was not 
important at all would get a score of 3 while someone who said both were extremely important would get a score of 0 . So, the further the distance of importance between values, the higher the score.

Next, feelings about welfare beneficiaries are measured with two additive indices, one for positive feelings and another for negative feelings. These indices based on answers to two questions tapping respondents' affect toward "poor people" and "blacks" are used for the measures of cognitiveaffective and affective conflict. Respondents were read the following introduction:

Next, I'd like to do the same thing except with a list of different government
institutions and groups that are active in politics. Once again: If you do not
have any positive feelings toward the institution or group, give it the lowest
rating of 1; if you have some positive feelings, rate it a 2; if you have gener-
ally positive feelings, rate it a 3 ; and if you have extremely positive feelings,
rate it a 4. Please rate each institution or group based solely on how positively
you feel about it, while ignoring or setting aside for the moment any negative
feelings you may have. The first group is ...

The names of the groups and institutions were then read (including poor people and blacks) and respondents were asked to rate each one separately. Then, as with social welfare items, the introduction was repeated except with the words "positive" and "positively" replaced by "negative" and "negatively" following a number of filler questions. As before, scores range from 1 (no positive/negative feelings) to 4 (extremely positive/negative feelings) and from 2-8 after summing each respectively. The positive items and negative items scaled well together, indicating that people shared similar feelings across these two groups (positive feelings $\alpha=.772$; negative feelings $\alpha=$ $.868)$.

These indices were used in combination with the values indicators described in the previous section to construct a measure of cognitiveaffective conflict. The idea here is that we should expect conflict between individualist values and positive feelings about the perceived beneficiaries and between egalitarian values and negative feelings about the perceived beneficiaries to stimulate ambivalence. It is not logical to suggest that individualist values will come into conflict with negative feelings about the beneficiaries or for egalitarian values to conflict with positive feelings because each has the same directional effect on attitude about social welfare. Rather than creating separate measures for each, the scale for positive feelings about the beneficiary and individualist values is inverted and each is added to negative feelings about the beneficiary and egalitarian values respectively. Flipping the scales gives them the same directional effect on attitudes about social welfare. Because there is no reason to expect that conflict is more likely to stimulate ambivalence for individualist/positive 
feelings or egalitarian/negative feelings conflict, inverting the scales permits one measure of cognitive-affective conflict. After summing the inverted scales with the non-inverted scales, each is rescaled so that all values fall between 0 and 1 . The same algorithm as used above is again employed to create a scale of cognitive-affective conflict. The resulting scale is also normalized to have values between 0 and 1 .

A measure of affective conflict is created by summing the positive responses to poor people and blacks, summing the negative responses to poor people and blacks, and then using the same algorithm to juxtapose positive responses against negative responses. Next, this scale is recoded to have values that range between 0 and 1 . Descriptions of all other control variables used are included in the appendix.

\section{Analysis}

\section{Prevalence of Ambivalence}

Before moving on to a comparison of relative validity of each of the measures employed here, it is useful to see how much ambivalence each measure suggests is actually present. If any of the measures used here are actually capturing ambivalence they must indicate that ambivalence is indeed present. The operative measure that requires respondents to rate their positive and negative feelings separately suggests that ambivalence is quite prevalent. In fact, when it came to how people felt about ensuring that every citizen has adequate medical insurance 26 people (4.3\%) gave a score of 4 and 4 for extremely positive and extremely negative feelings, 14 people $(2.3 \%)$ gave the same concerning providing programs to help homeless people, 41 people $(6.8 \%)$ offered a $4-4$ response regarding ensuring that every child has access to a good education, and 13 people $(2.1 \%)$ gave this response concerning providing programs that improve the standard of living of poor Americans. As for seeing to it that everyone who wants a job has one, 23 people (3.8\%) gave a $4-4$ response, 26 people $(4.3 \%)$ did the same concerning providing childcare programs to assist working parents, and 44 people $(7.2 \%)$ did so when asked about ensuring that the retirement benefits that citizens have built up over the years are protected At first these percentages may seem small, but considering these estimates only count those with the highest ambivalence score possible, it is quite astonishing. Further, more than half of the sample on many of the issues gave responses that were at least moderately conflicted (scores of at least 2 and 1).

Concerning the operative measure that is based on residuals, there is no direct way to gauge the prevalence of ambivalence. This is a shortcoming of the measure. As noted previously, we can only infer the presence by how 
Table 1. Correlations across Meta-Attitudinal and Operative Measures of Ambivalence

\begin{tabular}{|c|c|c|c|c|}
\hline & $\begin{array}{l}\text { Meta- } \\
\text { attitudinal } \\
\text { "Torn" }\end{array}$ & $\begin{array}{c}\text { Meta- } \\
\text { attitudinal } \\
\text { "Volunteered" }\end{array}$ & $\begin{array}{l}\text { Operative } \\
\text { "Residuals }\end{array}$ & $\begin{array}{l}\text { Operative } \\
\text { "Pos/Neg" }\end{array}$ \\
\hline Meta-attitudinal "Torn” & 1.00 & - & - & - \\
\hline Meta-attitudinal "Volunteered" & - & 1.00 & - & - \\
\hline Operative "Residuals" & $0.31 *$ & $0.23 *$ & 1.00 & - \\
\hline Operative "Pos/Neg" & 0.06 & -0.08 & $0.13^{*}$ & 1.00 \\
\hline \multicolumn{5}{|c|}{$\begin{array}{l}\text { Note: Data are from a Florida Voter survey of registered voters conducted in May } 2004 \text {. The twe } \\
\text { direct variables cannot be correlated because they are each part of the same split-sample indicator } \\
\text { Table entries are Kendall's tau }{ }_{b} \text { correlation coefficients. } 2 \text {-tailed test } * \mathrm{p} \leq 0.05 \text {. }\end{array}$} \\
\hline
\end{tabular}

well the predictors correlate to the measure. As for the meta-attitudinal measures, while not to the degree of the other operative measure, they also suggest that ambivalence is fairly prevalent. When offered the "torn" response, about 24 percent of the respondents selected it, and about 13 percent of the sample volunteered a mixed response.

\section{Empirically Comparing Measurement Approaches}

Table 1 contains the zero-order correlations between each of the measures of social welfare ambivalence. There is not a strong relationship between any of these measures. There is a very weak positive relationship between the two operative measures $(0.13)$. There is a significant correlation between the meta-attitudinal measures and the operative residuals measure, but this relationship is suspect because the residuals and the meta-attitudinal measures are based on the same indicator. The lack of correlation across these measures suggests they are not all capturing ambivalence. These results mirror the findings of previous research that suggested there was not a strong relationship between meta-attitudinal and operative ambivalence (Mulligan and McGraw 2002; Newby-Clark, McGregor, and Zanna 2002; Priester and Petty 2001), but also demonstrates that there is not much of a relationship between the two operative measures.

The approach to analyzing the operative residuals measure employed by Alvarez and Brehm (1995, 1997, 1998, and 2002) is replicated before moving to a multivariate analysis of each of the measures. The replication involves comparing the variance across levels of cognitive, cognitiveaffective, and affective conflict. The expectation is that the variance should be higher among those with more conflict. While this operative approach has 
shortcomings, it is replicated to give it the benefit of the doubt. The problem with this approach is two-fold. First, the measure of ambivalence is error variance. This variance could be high for reasons other than ambivalence (non-attitude, uncertainty). Second, the analysis gives us only aggregate inferences and ambivalence is an individual-level phenomenon. The latter problem is resolved later in this study by modeling the individual-level residuals as function of the sources and controls. ${ }^{10}$ Nonetheless, this approach has been used; so replicating it may verify that it is problematic.

For this analysis, a dummy variable is created for each source of ambivalence that represents above-average conflict $(0=$ below mean, $1=$ above mean). Next, the between-group variance is analyzed. A one-way analysis of variance (ANOVA) is employed to test for the homogeneity of variance across groups (below mean, above mean). This involves getting a Levene statistic (the test statistic for a homogeneity of variances test) and the associated probability. This probability tells us the likelihood with which we can confidently reject the null hypothesis and accept the hypothesis that there is higher error variance when predicting attitudes about social welfare for those with higher levels of conflict as opposed to those with lower levels.

The results of the analysis in Table 2 indicate that, other than cognitive conflict, the sources of ambivalence are not strong predictors of the error variance from the model of attitudes about social welfare. For that matter, the effect of cognitive conflict is in the opposite of the expected direction. These findings suggest that those who are less conflicted when it comes to values are actually more ambivalent. Further, the variance is higher for those with below average cognitive-affective and affective conflict, but this difference is not significant. If anything, this analysis tells us that the residuals are not a good measure of ambivalence (assuming that these measures of conflict are sources of ambivalence).

It is important that we look at the relationship between the sources of ambivalence before moving on to the multivariate analysis of the residuals and other measures of ambivalence. Because each of these measures uses overlapping items to create scales, multicollinearity is potentially an issue. If these scales correlate highly, they contribute redundant information and can cause other variables to appear to be less important than they really are. Bivariate analysis indicates that the cognitive-affective conflict scale is related to the affective scale $\left(\operatorname{tau}_{\mathrm{b}}=0.62, \mathrm{p} \leq 0.05\right)$ but not the cognitive conflict scale. Two separate models ordered-logit will be estimated for each dependent variable to address the problem of multicollinearity: one with cognitive-affective conflict and another with affective conflict. The dependent variables are distributed ordinally making an ordered-logit equation the best fit to the data. 


\section{Table 2. Analysis of Residuals from Model of Attitudes about Social Welfare}

\begin{tabular}{|c|c|c|c|}
\hline & $\begin{array}{l}\text { Variance } \\
\text { Residuals }\end{array}$ & Statistic & Probability \\
\hline \multicolumn{4}{|l|}{ Comparison 1} \\
\hline Above-average Cognitive Conflict & 1.90 & \multirow[b]{2}{*}{.05} & \multirow[b]{2}{*}{0.01} \\
\hline Below-average Cognitive Conflict & 2.29 & & \\
\hline \multicolumn{4}{|l|}{ Comparison 2} \\
\hline Above-average Cognitive-Affective Conflict & 1.99 & \multirow[b]{2}{*}{.00} & \multirow[b]{2}{*}{0.99} \\
\hline Below-average Cognitive-Affective Conflict & 2.02 & & \\
\hline \multicolumn{4}{|l|}{ Comparison 3} \\
\hline Above-average Affective Conflict & 1.90 & \multirow[b]{2}{*}{.39} & \multirow[b]{2}{*}{0.24} \\
\hline Below-average Affective Conflict & 2.11 & & \\
\hline \multicolumn{4}{|c|}{$\begin{array}{l}\text { Note: Data are from a Florida Voter survey of registered voters conducted in May } 2004 \text {. The first } \\
\text { column gives the within-group variances of the Ordered-Logit equation of social welfare attitudes. } \\
\text { The second column gives the Levene statistic (the test statistic for a homogeneity of variances test). } \\
\text { The observed probability value from this test is in the third column. }\end{array}$} \\
\hline
\end{tabular}

The models used to compare the relative construct validity of the four ambivalence measures are as follows:

\section{Model 1}

Social Welfare Ambivalence $=a+\beta 1$ Cognitive Conflict $+\beta 2$ Egalitarianism Importance $+\beta 3$ Individualism Importance $+\beta 4$ Relative Importance of Values $+\beta 5$ Cognitive-Affective Conflict $+\beta 7$ Female $+\beta 8$ Black + Income $+\beta 9$ Political Knowledge $+e$

\section{Model 2}

Social Welfare Ambivalence $=a+\beta 1$ Cognitive Conflict $+\beta 2$ Egalitarianism Importance $+\beta 3$ Individualism Importance $+\beta 4$ Relative Importance of Values $+\beta 5$ Affective Conflict $+\beta 7$ Female $+\beta 8$ Black + Income $+\beta 9$ Political Knowledge $+e$

While this prevents the simultaneous estimation of the relationship between cognitive-affective conflict, affective conflict, and social welfare ambivaence, it does resolve the problem with multicollinearity. 
Table 3. Comparing Meta-Attitudinal Measurement Approaches

\begin{tabular}{|c|c|c|c|c|}
\hline & \multicolumn{2}{|c|}{ Torn } & \multicolumn{2}{|c|}{ Volunteered } \\
\hline & Model 1 & Model 2 & Model 1 & Model 2 \\
\hline Cognitive Conflict & $\begin{array}{c}0.77 \\
(0.56)\end{array}$ & $\begin{array}{c}0.73 \\
(0.56)\end{array}$ & $\begin{array}{l}2.13 * * \\
(0.78)\end{array}$ & $\begin{array}{l}2.16^{* *} \\
(0.79)\end{array}$ \\
\hline Cognitive-Affective Conflict & $\begin{array}{l}-0.41 \\
(0.60)\end{array}$ & - & $\begin{array}{l}-1.97 * * \\
(0.90)\end{array}$ & - \\
\hline Affective Conflict & - & $\begin{array}{l}-0.15 \\
(0.51)\end{array}$ & - & $\begin{array}{l}-1.40 * * \\
(0.82)\end{array}$ \\
\hline Egalitarianism Importance & $\begin{array}{l}-0.01 \\
(0.17)\end{array}$ & $\begin{array}{l}-0.01 \\
(0.17)\end{array}$ & $\begin{array}{l}-0.59^{* *} \\
(0.22)\end{array}$ & $\begin{array}{l}-0.25^{* *} \\
(0.09)\end{array}$ \\
\hline Individualism Importance & $\begin{array}{c}0.16 \\
(0.17)\end{array}$ & $\begin{array}{c}0.16 \\
(0.17)\end{array}$ & $\begin{array}{l}-0.10 \\
(0.22)\end{array}$ & $\begin{array}{l}-0.12 \\
(0.23)\end{array}$ \\
\hline Relative Difference & $\begin{array}{c}0.04 \\
(0.18)\end{array}$ & $\begin{array}{c}0.04 \\
(0.18)\end{array}$ & $\begin{array}{l}-0.05 \\
(0.22)\end{array}$ & $\begin{array}{l}-0.01 \\
(0.22)\end{array}$ \\
\hline Black & $\begin{array}{l}-1.12 * \\
(0.65)\end{array}$ & $\begin{array}{l}-1.12 * \\
(0.65)\end{array}$ & $\begin{array}{c}0.86 \\
(0.60)\end{array}$ & $\begin{array}{c}0.84 \\
(0.60)\end{array}$ \\
\hline Female & $\begin{array}{l}0.83^{* *} \\
(0.30)\end{array}$ & $\begin{array}{l}0.83^{* *} \\
(0.30)\end{array}$ & $\begin{array}{l}-0.26 \\
(0.38)\end{array}$ & $\begin{array}{l}-0.28 \\
(0.38)\end{array}$ \\
\hline Income & $\begin{array}{c}0.02 \\
(0.15)\end{array}$ & $\begin{array}{c}0.02 \\
(0.15)\end{array}$ & $\begin{array}{c}0.33^{*} \\
(0.20)\end{array}$ & $\begin{array}{c}0.33^{*} \\
(0.19)\end{array}$ \\
\hline Political Knowledge & $\begin{array}{l}-0.20 \\
(0.15)\end{array}$ & $\begin{array}{l}-0.20 \\
(0.15)\end{array}$ & $\begin{array}{l}-0.16 \\
(0.20)\end{array}$ & $\begin{array}{l}-0.16 \\
(0.20)\end{array}$ \\
\hline Constant & $\begin{array}{c}1.91 \\
(1.00)\end{array}$ & $\begin{array}{c}2.02 * \\
(1.01)\end{array}$ & $\begin{array}{c}0.93 \\
(1.37)\end{array}$ & $\begin{array}{c}0.93 \\
(1.37)\end{array}$ \\
\hline-2 log likelihood & 317.76 & 318.15 & 200.40 & 202.66 \\
\hline Nagelkerke Pseudo $\mathrm{R}^{2}$ & 0.08 & 0.08 & 0.17 & 0.16 \\
\hline $\mathrm{N}$ & 304 & 304 & 303 & 303 \\
\hline
\end{tabular}

We get a better test of construct validity than the bivariate relationships presented above (Table 1) by looking at how well these models perform across all four measures of ambivalence. Table 3 contains the results of estimating the equations that model each of the two meta-attitudinal measures of ambivalence as a function of the potential sources of ambivalence. Controls are also included. The meta-attitudinal models where respondents "volunteered" mixed responses perform better than those where they were given 
Table 4. Comparing Operative Measurement Approaches

\begin{tabular}{|c|c|c|c|c|}
\hline & \multicolumn{2}{|c|}{ Residuals } & \multicolumn{2}{|c|}{ Pos/Neg } \\
\hline & Model 1 & Model 2 & Model 1 & Model 2 \\
\hline Cognitive Conflict & $\begin{array}{c}0.47 \\
(0.30)\end{array}$ & $\begin{array}{c}0.51 \\
(0.30)\end{array}$ & $\begin{array}{l}1.31 * * \\
(0.29)\end{array}$ & $\begin{array}{l}1.52 * * \\
(0.29)\end{array}$ \\
\hline Cognitive-Affective Conflict & $\begin{array}{c}0.62 \\
(0.33)\end{array}$ & - & $\begin{array}{l}3.41 * * \\
(0.34)\end{array}$ & - \\
\hline Affective Conflict & - & $\begin{array}{c}0.35 \\
(0.28)\end{array}$ & - & $\begin{array}{l}3.92 * * \\
(0.30)\end{array}$ \\
\hline Egalitarianism Importance & $\begin{array}{l}-0.10 \\
(0.09)\end{array}$ & $\begin{array}{l}-0.10 \\
(0.09)\end{array}$ & $\begin{array}{l}-0.37 * * \\
(0.09)\end{array}$ & $\begin{array}{l}-0.25^{* *} \\
(0.09)\end{array}$ \\
\hline Individualism Importance & $\begin{array}{c}0.12 \\
(0.09)\end{array}$ & $\begin{array}{c}0.17 \\
(0.09)\end{array}$ & $\begin{array}{l}-0.38^{* *} \\
(0.09)\end{array}$ & $\begin{array}{l}-0.28 * * \\
(0.09)\end{array}$ \\
\hline Relative Difference & $\begin{array}{l}-0.12 \\
(0.09)\end{array}$ & $\begin{array}{l}-0.13 \\
(0.09)\end{array}$ & $\begin{array}{l}-0.17 * \\
(0.09)\end{array}$ & $\begin{array}{l}-0.17 * * \\
(0.09)\end{array}$ \\
\hline Black & $\begin{array}{l}-0.19 \\
(0.28)\end{array}$ & $\begin{array}{l}-0.18 \\
(0.28)\end{array}$ & $\begin{array}{l}-1.03 * * \\
(0.26)\end{array}$ & $\begin{array}{l}-0.98^{* *} \\
(0.27)\end{array}$ \\
\hline Female & $\begin{array}{l}-0.16 \\
(0.15)\end{array}$ & $\begin{array}{l}-0.17 \\
(0.15)\end{array}$ & $\begin{array}{l}-0.20 \\
(0.15)\end{array}$ & $\begin{array}{l}-0.26^{*} \\
(0.15)\end{array}$ \\
\hline Income & $\begin{array}{l}-0.08 \\
(0.08)\end{array}$ & $\begin{array}{l}-0.08 \\
(0.08)\end{array}$ & $\begin{array}{c}0.02 \\
(0.08)\end{array}$ & $\begin{array}{c}0.06 \\
(0.08)\end{array}$ \\
\hline Political Knowledge & $\begin{array}{l}-0.12 \\
(0.08)\end{array}$ & $\begin{array}{l}-0.12 \\
(0.08)\end{array}$ & $\begin{array}{c}0.08 \\
(0.08)\end{array}$ & $\begin{array}{c}0.03 \\
(0.08)\end{array}$ \\
\hline$-2 \log$ likelihood & 1759.00 & 1762.48 & 4239.78 & 4164.25 \\
\hline Nagelkerke Pseudo $\mathrm{R}^{2}$ & 0.03 & 0.03 & 0.29 & 0.37 \\
\hline $\mathrm{N}$ & 607 & 607 & 607 & 607 \\
\hline
\end{tabular}

the "torn between sides" option. Cognitive conflict and egalitarianism importance are significant in the expected direction in the volunteered model. On the other hand, cognitive-affective conflict is significant but not in the expected direction. The findings here suggest that ambivalence goes down as this type of conflict goes up, ceteris paribus. While this model does have some reliable predictors in the right direction, the total number of respondents who volunteered a mixed response is low $(\mathrm{n}=38)$, so it is likely many who are ambivalent selected some other response. 


\section{8 | Jason Gainous}

None of the sources of ambivalence are significant in the "torn" models. This meta-attitudinal measure must be capturing something other than ambivalence (assuming the measures of conflict are valid). Basilli (1996) might suggest this meta-attitudinal measure is capturing people's direct reaction to possessing positive and negative evaluations about social welfare. Obviously these reactions are not correlated with the sources of ambivalence, or the model would pick that up. In sum, the lack of findings across the meta-attitudinal measures suggests that they are not good measures of ambivalence.

With the exception of the race and gender controls, there are no significant estimated effects in the model of the residuals (Table 4). These findings suggest that this is a poor measure of ambivalence. The final model that uses the combined positive and negative evaluations performs the best. Cognitive conflict, value importance and the relative difference of value importance, cognitive-affective conflict, affective conflict, race, and gender are all significant and in the expected direction. This makes sense if we think of ambivalence as an attribute of attitudes. If ambivalence is the simultaneous possession of positive and negative evaluations of a single attitude object, then this measure makes the most intuitive sense, and based on these data, the most empirical sense.

\section{Discussion}

It is important that both researchers and "real world" practitioners develop an effective way to measure ambivalence. Presumably, researchers, campaigners, news organizations, and candidates are all interested in measures that are valid. Standard indicators included in the major surveys utilized in the discipline (e.g. American National Election Studies and General Social Survey) and in traditional benchmark and tracking polls offer no systematic way of distinguishing those who are ambivalent from those who are not. This means that the results of these surveys are questionable and potentially misleading.

In this study, I compared several approaches to measuring ambivalence. The construct validity of each of the different measures was assessed by comparing how well the theoretical sources of ambivalence predict each measure respectively. The findings indicate that the approach adapted from earlier work (Craig, Kane, and Martinez 2002; Craig, Martinez, and Kane 2005) that forces respondents to rate their positive and negative feelings separately is the most valid if we agree that ambivalence can be defined as the simultaneous possession of positive and negative evaluations. The evidence provides support to previous research that suggested ambivalence may result when individuals have conflicting thoughts or beliefs (cognitive 
conflict), conflicting feelings (affective conflict), or beliefs in conflict with feelings (cognitive-affective conflict). It is important to note the metaattitudinal measures here may be capturing something other than ambivalence, strictly defined. Holbrook and Krosnick (2005) looked extensively at consequences of meta-attitudinal ambivalence but more needs to be done the potential antecedents of such ambivalence. This will provide a more complete understanding of the concept in general, as well as the differences between these measures.

While it seems that the operative approach used here is the most accurate measure of ambivalence, this does not necessarily mean that we should always incorporate this approach in future surveys. As noted above, this is a time consuming and costly approach because every object must be evaluated twice. Nonetheless, the evidence presented here is eye-opening. For decades in survey research, we have been asking people how they feel about various issues but have typically failed to consider the possibility that attitudes are not uni-polar. The idea that people were willing to answer a telephone and tell somebody that they had extremely positive feelings and extremely negative feelings about the same thing is remarkable. More than just a few people did so, and they did so for multiple policies. Furthermore, they were willing to do so just a few minutes apart.

In conclusion, this widespread ambivalence speaks volumes about what goes on in American politics and elections today. The people who simultaneously choose extremely positive and extremely negative responses toward a host of social welfare items are the same people whom candidates are trying to court by taking positions on issues such as social welfare. How can they effectively gauge what their constituents want without a measure that represents their "true" opinion? And, how can researchers be confident in their explanations of social welfare attitudes? The results here are certainly a starting point, but more needs to be done to both explore the consequences and measurement of ambivalence. When public opinion researchers find agreement on the optimal approach to measuring social welfare ambivalence and ambivalence in general, there are a plethora of questions that can be revisited and pioneered. For instance, is the relationship between issue positions and candidate evaluations moderated by ambivalence, are those who are ambivalent more or less open to elite influence on those issues for which they are ambivalent, are voters more or less inclined to prioritize those issues for which they are ambivalent, and are ambivalent attitudes stable or do people resolve their ambivalence? If so, how does this occur? These are just a few of the questions that can be addressed. 


\section{APPENDIX Additional Independent Variables}

Race- $(0=$ non-black, 1 = black $)$

Gender- $(0=$ male, 1 = female $)$

Self reported income- (collapsed into 5 categories: less than $\$ 10,000$, between $\$ 10,000$ and $\$ 30,000$, between $\$ 30,000$ and $\$ 50,000$, between $\$ 50,000$ and $\$ 70,000, \$ 70,000$ or more).

Political knowledge - Respondents were read the following introduction:

Here are a few questions about the government in Washington. Many people don't know the answers to these questions, but even if you're not sure I'd like you to tell me your best guess.

Then they were asked the following questions:

1. First, do you happen to know what job or political office is currently held by John Ashcroft?

2. Who has the final responsibility to decide if a law is constitutional or not-is it the president, Congress, or the Supreme Court?

3. Would you say that one of the parties is more conservative than the other at the national level? If yes: Which party is more conservative? (ROTATE)?

Dummy variables were created for each correct response $(0=$ incorrect, $1=$ correct $)$. Then an additive index was constructed by adding the three together. Higher values represent more political knowledge.

\section{NOTES}

${ }^{1}$ Their study was based on an experiment but the booklets participants were asked to complete are comparable to surveys. Of course the sample is different than that in typical survey (completely random), but the question wording was set up like a survey.

${ }^{2}$ Nelson (1999) does suggest that cognitive elements of outgroup attitudes dominate affect in their influence on policy opinion, but this study is not concerned with the primacy of one effect over another.

${ }^{3}$ Additional information can be obtained from the author, or from Florida Voter directly (954-584-0204). In order to avoid an unacceptable loss of cases in the analysis, I employed the MICE ("multiple imputation using chained equations"; see Horton and Lipsitz 2001) routine in the R statistical package to impute missing data. MICE does this by replacing each missing value with a random draw from a distribution estimated from a maximum likelihood function based on other variables in the dataset. The imputed dataset was based on the mean values from five replicate datasets created by MICE.

${ }^{4}$ This model is derived from a version of the semantic differential (Osgood, Suci, and Tannenbaum 1957), as modified by Kaplan (1972) in an effort to show that people's overall attitudes are made up of both positive and negative elements. Thompson and her colleagues (1995) adjusted the model to better account for the presence of polarized beliefs. See Craig, Kane, and Martinez (2002) for a more complete discussion of this measure as employed in a large-sample survey. 
${ }^{5}$ A dummy variable is added for the question form to the multivariate analysis presented below to control for any question format effect. The coefficient for the form dummy was trivial.

${ }^{6}$ Three of the seven independent variables reach traditional levels of statistical significance $(\mathrm{p} \leq 0.05)$. Those who are more individualist are less likely to feel positively about social welfare. Conversely, egalitarianism is positively associated with support for social welfare. Republicans are less likely to feel positive than are independents or Democrats.

${ }^{7}$ These questions were designed to tap support for economic individualism, or a belief in the freedom to accumulate wealth. Scholars with a different substantive focus might prefer to measure individualism differently, for example, conceptualizing it in terms of a belief in freedom of expression.

${ }^{8}$ These items did not scale that well together ( $\operatorname{taub}=0.16, \mathrm{p}<0.05$ for the individualist items and taub $=0.22, \mathrm{p}<0.05$ for the egalitarian items). These items were based on measures from ANES and they scale well together in those data but the approach here varies slightly. The companion statements used here in each indicator are derived from two separate indicators from ANES. This allowed for the use of multiple measures with fewer questions on the survey. Perhaps collapsing two items into each indicator decreased the validity, as opposed to having four separate questions for each.

${ }^{9}$ The survey included a measure of the importance of traditional moral values, which was asked in between the two indicators used here.

${ }^{10}$ For an example of the same method using ordinary least squares regression see Marks et al. (2004).

\section{REFERENCES}

Albertson, Bethany, John Brehm, and R. Michael Alvarez. 2005. Ambivalence as Internal Conflict. In Ambivalence and the Structure of Political Opinion, eds. Stephen C. Craig and Michael D. Martinez. New York: Palgrave Macmillan.

Alvarez, R. Michael, and John Brehm. 1995. American Ambivalence towards Abortion Policy: Development of a Heteroskedastic Probit Model of Competing Values. American Journal of Political Science 39(4):1055-1082.

Alvarez, R. Michael, and John Brehm. 1997. Are Americans Ambivalent Towards Racial Policies? American Journal of Political Science 41(2):345-374.

Alvarez, R. Michael, and John Brehm. 1998. Speaking in Two Voices: American Equivocation about the Internal Revenue Service. American Journal of Political Science 42:418-452.

Alvarez, R. Michael, and John Brehm. 2002. Hard Choices, Easy Answers: Values, Information, and American Public Opinion. Princeton, NJ: Princeton University Press.

Armitage, Christopher J., and Mark Conner. 2000. Attitudinal Ambivalence: A Test of Three Key Hypotheses. Personality and Social Psychology Bulletin 26:1421-1432.

Bassili, John N. 1996. Meta-Judgmental Versus Operative Indexes of Psychological Attributes: The Case of Measures of Attitude Strength. Journal of Personality and Social Psychology 71:637-53.

Bobo, Lawrence, and James R. Kluegel. 1993. Opposition to Race Targeting: Selfinterest, Stratification Ideology, or Racial Attitudes. American Sociological Review 58(4):443-464. 
Boninger, David S., Jon A. Krosnick, and Matthew K. Berent. 1995. Origins of Attitude Importance: Self-Interest, Social Identification, and Value Relevance. Journal of Personality and Social Psychology 68:61-80.

Cantril, Albert H., and Susan D. Cantril. 1999. Reading Mixed Signals: Ambivalence in American Public Opinion about Government. Washington, DC: Woodrow Wilson Center Press.

Cacioppo, John T., Wendi Gardner, and Gary G. Berntson. 1997. Beyond Bipolar Conceptualizations and Measures: The Case of Attitudes and Evaluative Space. Personality and Social Psychology Review 1:3-25.

Cook, Fay Lomax, and Edith J. Barrett. 1992. Support for the American Welfare State: The Views of Congress and the Public. New York: Columbia University Press.

Craig, Stephen C., James G. Kane, and Michael D. Martinez. 2002. Sometimes You Feel Like a Nut, Sometimes You Don't: Citizens' Ambivalence about Abortion. Political Psychology 23(2):285-301.

Craig, Stephen C., Michael D. Martinez, and James G. Kane. 2005. Ambivalence and Response Instability: A Panel Study. In Ambivalence and the Structure of Political Opinion, eds. Stephen C. Craig and Michael D. Martinez. New York: Palgrave Macmillan.

Craig, Stephen C., Michael D. Martinez, James G. Kane, and Jason Gainous. 2005. Core Values, Value Conflict, and Citizens' Ambivalence about Gay Rights. Political Research Quarterly 58(1):5-17.

Eagly, Alice H., and Shelly Chaiken. 1993. The Psychology of Attitudes. Fort Worth, TX: Harcourt Brace.

Feldman, Stanley, and John Zaller. 1992. The Political Culture of Ambivalence: Ideological Responses to the Welfare State. American Journal of Political Science 36(1):268-307.

Fiske, Susan T., and Shelly E. Taylor. 1991. Social Cognition, 2nd ed. New York: McGraw-Hill.

Gainous, Jason, and Michael D. Martinez. 2005. What Happens When We Simultaneously Want Opposite Things? Ambivalence about Social Welfare. In Ambivalence, Politics, and Public Policy, eds. Stephen C. Craig and Michael D. Martinez. New York: Palgrave Macmillan.

Gilens, Martin. 1988. Gender and Support for Reagan: A Comprehensive Model of Presidential Approval. American Journal of Political Science 32:19-49.

Gilens, Martin. 1995. Racial Attitudes and Opposition to Welfare. Journal of Politics 57(4):994-1014.

Goren, Paul. 2001. Core Principles and Policy Reasoning in Mass Publics: A Test of Two Theories. British Journal of Political Science 31:159-177.

Hodson, Gordon, Gregory R. Maio, and Victoria M. Esses. 2001. The Role of Attitudinal Ambivalence in Susceptibility to Consensus Information. Basic and Applied Social Psychology 23:197-205.

Holbrook, Allyson L., and Jon A. Krosnick. 2005. Meta-Psychological Versus Operative Measures of Ambivalence: Differentiating the Consequences of Perceived IntraPsychic Conflict and Real Intra-Psychic Conflict. In Ambivalence and the Structure of Political Opinion, eds. Stephen C. Craig and Michael D. Martinez. New York: Palgrave Macmillan.

Horton, Nicholas J., and Stuart R. Lipsitz. 2001. Multiple Imputation in Practice: Comparison of Software Packages for Regression Models with Missing Variables. The American Statistician 55:244-254. 
Jacoby, William. G. 2002. Core Values and Political Attitudes. Pp. 177-201 in Understanding Public Opinion, 2nd ed., eds. Barbara Norrander and Clyde Wilcox. Washington, DC: CQ Press.

Jacoby, William G. 2005. Is It Really Ambivalence? Public Opinion toward Government Spending. In Ambivalence and the Structure of Political Opinion, eds. Stephen C. Craig and Michael D. Martinez. New York: Palgrave Macmillan.

Kaplan, Kalman J. 1972. On the Ambivalence-Indifference Problem in Attitude Theory and Measurement: A Suggested Modification of the Semantic Differential Technique. Psychological Bulletin 77:361-372.

Katz, Irwin, and R. Glen Hass. 1988. Racial Ambivalence and American Value Conflict: Correlational and Priming Studies of Dual Cognitive Structures. Journal of Personality and Social Psychology 55(6):893-905.

Katz, Irwin, J. Wackenhut, and R. Glen Hass. 1986. Racial Ambivalence, Value Duality, and Behavior. Pp. 35-59 in Prejudice, Discrimination, and Racism, eds. John F. Dovidio and Samuel L. Gaertner. New York: Academic Press.

Kaufmann, Karen M., and John R. Petrocik. 1999. The Changing Politics of American Men: Understanding the Sources of the Gender Gap. American Journal of Political Science 43:864-887.

Kinder, Donald R., and Nicholas Winter. 2001. Exploring the Racial Divide: Blacks, Whites, and Opinion on National Policy. American Journal of Political Science 45(2):439-456.

Krosnick, Jon A. 1988. Attitude Importance and Attitude Change. Journal of Experimental Social Psychology 24:240-255.

Krosnick, Jon A., and Robert P. Abelson. 1992. The Case for Measuring Attitude Strength in Surveys. Pp. 177-203 in Questions about Questions: Inquiries into the Cognitive Bases of Surveys, ed. Judith M. Tanur. New York: Russell Sage.

Krosnick, Jon A., David S. Boninger, Yao C. Chuang, Mathew K. Berent, and Catherine G. Carnot. 1993. Attitude Strength: One Construct or Many Related Constructs? Journal of Personality and Social Psychology 65:1132-1151.

Lavine, Howard, and Marco Steenbergen. 2005. Group Ambivalence and Electoral Decision Making. In Ambivalence, Politics, and Public Policy, eds. Stephen C. Craig and Michael D. Martinez. New York: Palgrave Macmillan.

Marks, Gary, Liesbet Hooghe, Marco R. Steenbergen, and Ryan Bakker. 2004. Crossvalidating Data on Party Positioning on European Integration. Paper prepared for the Workshop Comparing Data Sets on Party Positioning. Amsterdam: Free University.

Martinez, Michael D., Stephen C. Craig, James G. Kane, and Jason Gainous. 2005. Ambivalence and Value Conflict: A Test of Two Issues. In Ambivalence, Politics, and Public Policy, eds. Stephen C. Craig and Michael D. Martinez. New York: Palgrave Macmillan.

McGraw, Kathleen M., Edward Hasecke, and Kimberly Conger. 2003. Ambivalence, Uncertainty, and Processes of Candidate Evaluation. Political Psychology 24:421448.

Mulligan, Kenneth, and Kathleen M. McGraw. 2002. Value Conflict: The Effects of Competing Principles on Political Judgment. Paper presented at the 2002 Annual Meetings of the American Political Science Association, Boston, MA.

Nelson, Thomas E. 1999. Group Affect and Attribution in Social Policy Opinion. Journal of Politics 61(2):331-362. 


\section{4 | Jason Gainous}

Newby-Clark, Ian R., Ian McGregor, and Mark P. Zanna. 2002. Thinking and Caring about Cognitive Inconsistency: When and for Whom does Attitudinal Ambivalence Feel Uncomfortable? Journal of Personality and Social Psychology 82:157-166.

Newby-Clark, Ian R., Ian McGregor, and Mark P. Zanna. 2005. Ambivalence and Accessibility: The Consequences of Accessible Ambivalence. In Ambivalence and the Structure of Political Opinion, eds. Stephen C. Craig and Michael D. Martinez. New York: Palgrave Macmillan.

Osgood, Charles E., George J. Suci, and Percy H. Tannenbaum. 1957. The Measurement of Meaning. Urbana: University of Illinois Press.

Popkin, Samuel L. 1991. The Reasoning Voter: Communication and Persuasion in Presidential Campaigns. Chicago: University of Chicago Press.

Priester, Joseph R., and Richard E. Petty. 1996. The Gradual Threshold Model of Ambivalence: Relating the Positive and Negative Bases of Attitudes to Subjective Ambivalence. Journal of Personality and Social Psychology 71:431-449.

Priester, Joseph R., and Richard E. Petty. 2001. Extending the Bases of Subjective Attitudinal Ambivalence: Interpersonal and Intrapersonal Antecedents of Evaluative Tension. Journal of Personality and Social Psychology 80:19-34.

Rokeach, Milton. 1973. The Nature of Human Values. New York: The Free Press.

Schwartz, Shalom H. 1992. Universals in the Content and Structure of Values: Theoretical Advances and Empirical Tests in 20 Countries. Pp. 1-65 in Advances in Experimental Social Psychology, vol. 25, ed. Mark P. Zanna. New York: Academic Press.

Sniderman, Paul M., Richard A. Brody, and Philip E. Tetlock. 1991. Reasoning and Choice: Explorations in Political Psychology. New York: Cambridge University Press.

Steenbergen, Marco R., and Paul R. Brewer. 2000. The Not-So-Ambivalent Public: Policy Attitudes in the Political Culture of Ambivalence. Pp. 101-142 in The Issue of Belief: Essays in the Intersection of Non-Attitudes and Attitude Change, eds. Willem E. Saris and Paul M. Sniderman. Amsterdam: The Amsterdam School of Communication Research, Universiteit van Amsterdam, The Netherlands.

Tate, Katherine. 1994. From Protest to Politics: The New Black Voters in American Elections. Cambridge, MA: Harvard University Press.

Thompson, Megan, Mark P. Zanna, and Dale W. Griffin. 1995. Let's Not Be Indifferent About (Attitudinal) Ambivalence. Pp. 361-386 in Attitude Strength: Antecedents and Consequences, eds. Richard E. Petty and Jon A. Krosnick. Mahwah, NJ: Lawrence Erlbaum.

Zaller, John R. 1992. The Nature and Origins of Mass Opinion. Cambridge: Cambridge University Press. 